\title{
Digital Literacy and Digital Skills in University Study
}

\author{
Galina Alexandrovna Abrosimova ${ }^{1}$ \\ ${ }^{1}$ Institute of International Relations, Kazan Federal University, Russia \\ Correspondence: Galina Alexandrovna Abrosimova, Institute of International Relations, Kazan Federal University, \\ Russia.E-mail: abrosimowagalina@yandex.ru
}

Received: September 3, 2020

Accepted: October 23, 2020

Online Published: October 31, 2020

doi:10.5430/ijhe.v9n8p52

URL: https://doi.org/10.5430/ijhe.v9n8p52

\begin{abstract}
Recently, the digitalization phenomenon has been trending upwards globally. This term has occupied all spheres of our lives, including education. Along with global tendencies and calls of the Industrial Revolution, 4.0 national projects outlined by the president in the particular project "Digital economy" have provided many impulses to the Digitalization of education.

This research paper is mainly devoted to exploring digital education and digital learning in Russia's realities today. The author utilizes the current situation with lockdown and, therefore, distance education and learning to try to shed light on some aspects of educational Digitalization. The article provides a theoretical discussion of the irreversibility and necessity of Digitalization of education, its components, stages, structure, advantages, and disadvantages; of what has been done and what is to be done in this field. The author also provides empirical data of studying Kazan Federal University students in foreign language classes during distance education and learning period. Remarkably, the article offers some insight into students' readiness for the digital era, evaluating their digital literacy and digital skills and competencies, their motivation to keep on studying while on distance, their abilities to take responsibility for their learning as well as some issues challenging students during distance learning.
\end{abstract}

Keywords: digitalization, digital communication, digital study, language study, literacy, university study

\section{Introduction}

In order to better understand the issue, we need to look closely into this term. Digitalization itself means the process of transition of a company or an entire economic industry to new models of business processes, management, and production methods based on information technology (Abrosimova et al., 2019: Kireeva et al, 2019).

The digitalization of a company is its transformation, where the leading role is of computer capital. In any organization, this process involves:

- $\quad$ gaining experience of technology using;

- finding competitive advantages of technologies;

- determining the direction and scope of the transformation;

- $\quad$ assessing the risks.

Also, it requires interrelation between three of its components. Which are:

- $\quad$ human assets (knowledge/ignorance, ability to learn, motivation, culture, mutual confidence, shared values);

- the capital stock of organization (approaches and principles of activity organizations, a delegation of responsibility, information)

- $\quad$ computer capital (information systems) (https://www.huffingtonpost.ca).

Thus the Digitalization of any organization/company demands thorough examination, so what about the Digitalization of education? The plainest definition means using computers, mobile devices, other hardware, the Internet, different software, and other digital technologies for teaching students of all ages (Abrosimova \& Kondrat'eva, 2018). However, the whole process of Digitalization is far more extensive. O.U. Ivanova gives the term 
the following definition: "Digitalization of education is a natural and logical way of education development in network society which is able to effectively and specifically address the whole range of inquiries of this community striving to limitless life-wide and life-long education (Kolykhmatov, 2019; Kivunja, 2015). Based on these, we can summarize that the Digitalization of education is a process of deep modernization and alteration of the education process in general in all training stages that meet every challenge of today's world.

\section{Materials and Methods}

The methodology used in research is theoretical, empirical. The author used methods of collecting data, statistical analysis processing, and description of the research results. The research focuses on assessing students' readiness for Digitalization of education and their current levels of digital skills that imply studying of state and normative documents, curricula and expecting results of training; materials and resources of distant learning, which is one of few options of learning due to the current epidemiologic situation. The study's collected experimental data has allowed outlining the advantages and disadvantages of using different distant learning online resources in the educational process. This paper uses data of Kazan federal university students' experience of non-tech and non-linguistic specialties studying English as a foreign language.

\section{Results and Discussing}

Digitalization implies automatization of all modern economic processes, starting with designing a product to its delivery to the consumer and following maintenance. In our rapidly changing world, employers want a workforce ready to work with the latest and newest technologies (Faleev \& Faleeva, 2018). It is estimated that 85\% of jobs of 2030 has not been invented yet (Ananin et al., 2018). Hence the need for employees who do not have special skills is decreasing fast, and the only solution to this problem is a complete transformation of the educational process, and higher educational institutes in their current mode will need to undergo dramatic changes (Sulianta et al., 2019). To date, however, the government has initiated several projects of priority like "Sovremennaya ciphrovaya obrazovatelnaya sreda v R.F./Modern digital educational environment in the Russian Federation" and "Ciphrovaya shkola/ Digital school" which are aimed to address the current challenges of education in the era of Digitalization. According to the paper by The Center for Strategic Research (CSR) and Higher School of Economics (HSE) "12 resheniy dlya novogo obrazobaniya/ 12 solutions for new education," the higher educational institutes is due to become innovation centers which will be a pillar of technological and innovative development of regions and states (https://www.bigdataschool.ru). The rapid development of science and technology innovations will increase the need for available advanced training and the acquisition of new skills throughout a career or perhaps even a cardinal change in the profession and career path, where universities will play one of the key roles.

Digitalization leads to a significant increase in the choice of courses and disciplines available for studying and international and interdisciplinary collaboration in science and research becomes easier. It also makes education more accessible and individual, and provides research freedom, and enhances autonomous learning. Autonomous learning leads to better acquisition of information and increasing of motivation to study. It looks like win-win situation (https://www.plm.automation.siemens.com; Morozov, 2018; https://www.hse.ru).

Nevertheless, according to data of the Modern digital educational environment in the Russian Federation, there is a less optimistic side of those changes. Like any other transformation, the process of Digitalization in education involves some risks, among them:

- $\quad$ low level of credence and determination of students and the academic community to use modern educational technologies based on digital content;

- $\quad$ low efficiency of applying teaching digitalization methods;

- $\quad$ the conservative perspective of educational organizations and institutions;

- low activity of employers and investors in supporting the development of high-quality digital content (https://www.arup.com).

Digitalization involves enhancing digital literacy and digital skills. Digital literacy is the possession of modern information technologies for work, life and the ability to search and evaluate and assess the information received; digital skill is a person's competence in the application of I.T. technologies, which are divided into general (applied in everyday life, like searching for information on the Internet, using office software, data analyzing and processing software, etc.) and professional (needed to create I.T. services and resources) and complementary, which are a blend 
of the first two types (like using social network and other digital messengers for work, etc.) (Kolykhmatov, 2018; Gilmanova, 2018; http://neorusedu.ru).

According to HSE statistics, the Russian Federation's most common digital skill is working with a text editor. It is mastered by about half of the population aged $15-74$ years (41.7\% in 2017). The rarest digital skill is writing software using programming languages individually by themselves. Only about $1 \%$ of the country's population has mastered it (1.2\% in 2017), and the plan is to make a competent digital population of $40 \%$ by 2024 (Mayevskaya, 2018). Achievement of this goal will not be possible without an appropriate level of competence of teachers and appropriate level of competence of students which are soon to get into the labor market, since in addition to developing infrastructure for the development of digital education, the human asset/potential is also of great importance. Summing it up, only through the modernization of education, continuous professional and self-development, and improvement, the development of digital skills and competencies of teachers and students, which includes:

- application of new educational technologies in the training process;

- modernizing the content of educational programs and curricula to develop the required competencies;

- development of informational and educational environment based on modern software and hardware systems; and only then will we be able to come to a qualitatively new education (Abdullina et al., 2019; Samerkhanova \& Imzharova, 2018).

In our research, we looked into the digital skills and competencies of 161 students (age 17-30) of non-tech specialties and their opinion about using different digital data while we are all forced to study from distant using different technologies, systems, and resources. Our goal was to assess their readiness for Digitalization and how do they assess it themselves.

In the first part of our survey, we gave them a questionnaire, similar to that of HSE, but fit to our reality of distant learning and asked how they would describe their skills of:

1. $\quad$ using text editing software/resources;

2. using photo, audio, video editing software/resources;

3. creating presentations;

4. installing new or reinstalling operating systems;

5. creating new software on their own, using programming languages.

Their answer options included the following:

- $\quad$ yes, I can use all the functions and options;

- $\quad y e s$, partly, but it is enough for me;

- yes, though there are problems sometimes, I have the Internet which helps me to solve all the problems;

- no, I cannot use it/them.

The results are shown in Diagram 1. As we expected, the number of students confidently using text editing resources and software is the majority: 74 students (46\% of respondents) answered that they have mastered text editing for 100 $\%$; another 62 students $(38,5 \%)$ said that they had mastered these skills only partially, but it's enough for their needs; 15 students (9\%) admitted that they sometimes have problems, but can solve it using the Internet, the other 9 students $(5,7 \%)$ refrained from answering. Bearing these in mind, we can sum it up by saying that the number of students possessing text editing skills of different levels is almost $98 \%$, which is a really excellent indicator. 


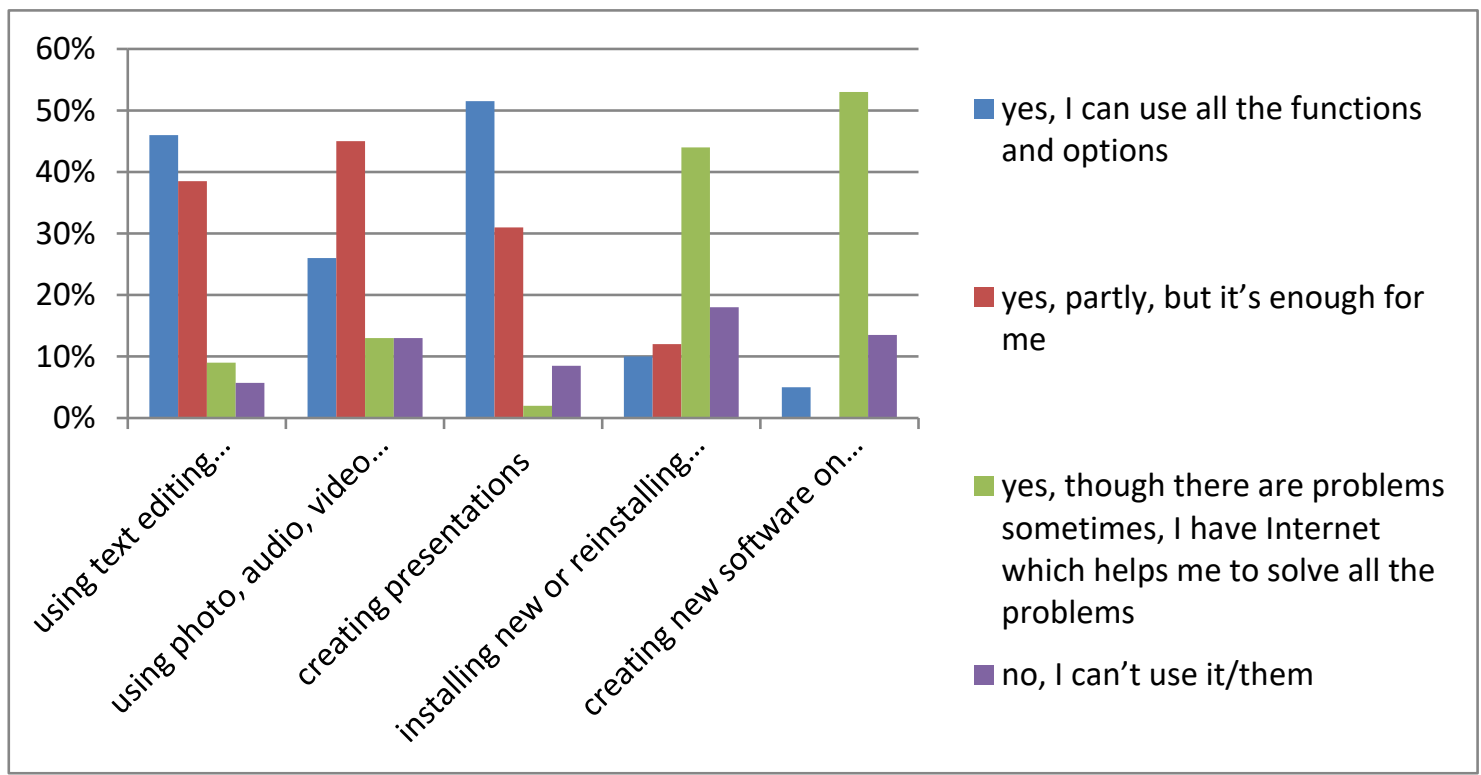

Diagram 1. Common digital skills of students

The second question was about their ability to use audio, video, and photo editing software/resources. Again, as we expected, the number of confident users of such software is a little lower comparing to the first question. Only 42 students (26\% of respondents) are $100 \%$ sure that they have mastered these skills completely. The bigger part, 72 people (45\%) think of their abilities as partly mastered, but enough for their own needs; 21 people (13\%) believe that their abilities are enough coupled with the Internet and the number of students not possessing these skills at all 13 $(8 \%)$, the same number refrained from giving an answer. According to our results, approximately $84 \%$ of respondents have skills to edit photos, video, and audio materials to a different degree.

The third question covered their ability to create presentations using M.S. PowerPoint and other software. Half of the students, 83 persons $(51.5 \%)$ are absolutely sure that they can complete these kinds of tasks using $100 \%$ of the given software and resources. About $31 \%$ of respondents (50 people) have decided that their abilities are not using all the potential power of resources and software, but fairly enough for them. Fourteen respondents (8.5\%) think that they can manage this task with the Internet's help, and 7\% of students (10 in number) do not have the required skills.

The following two questions are about more difficult skills, so the number of students possessing them strongly varies from the first three questions. For example, the number of students ultimately confidence in their skills of installing and reinstalling operative systems and creating new software on their own, using programming languages is only 10\% (16 people) and 5\% (8 people), respectively. The question about abilities to install and reinstall operative systems was answered: 'yes, partly, but it's enough for me' by $12 \%$ (19 people); 'yes, though there are problems sometimes, I have the Internet which helps me to solve all the problems' by $18 \%$ ( 29 people) and almost half of students $44 \%$ (71 people) answered no, that they would not be able to perform this task. The last question was answered negatively by 85 students (53\%), and this result was highly expected since it is the most challenging digital skill in our survey. Another 44 respondents (27\%) think that their current skills are not complete, but these skills are sufficient for their needs or can be completed by the Internet in case of need.

In the second part of the survey, students answered questions about their digital competencies. The first question asked them whether they think their digital competencies are adequate for our current distant learning system's realities. Their answers brought together in Diagram 2 were the following:

1) $21 \%$ of respondents ( 34 people) believe that their current digital competencies level is more than enough for distant learning;

2) $63 \%$ of respondents (100 people) think their competencies mostly sufficient though they admitted having some difficulties, but also being able to defeat them;

3) $13 \%$ of respondents ( 21 people) assumed their digital competencies only partially sufficient to current requirements; 
4) $1,8 \%$ of respondents ( 3 people) came to the conclusion that they do not possess adequate digital skills;

5) $1,2 \%$ of respondents (2people) found it difficult to answer.

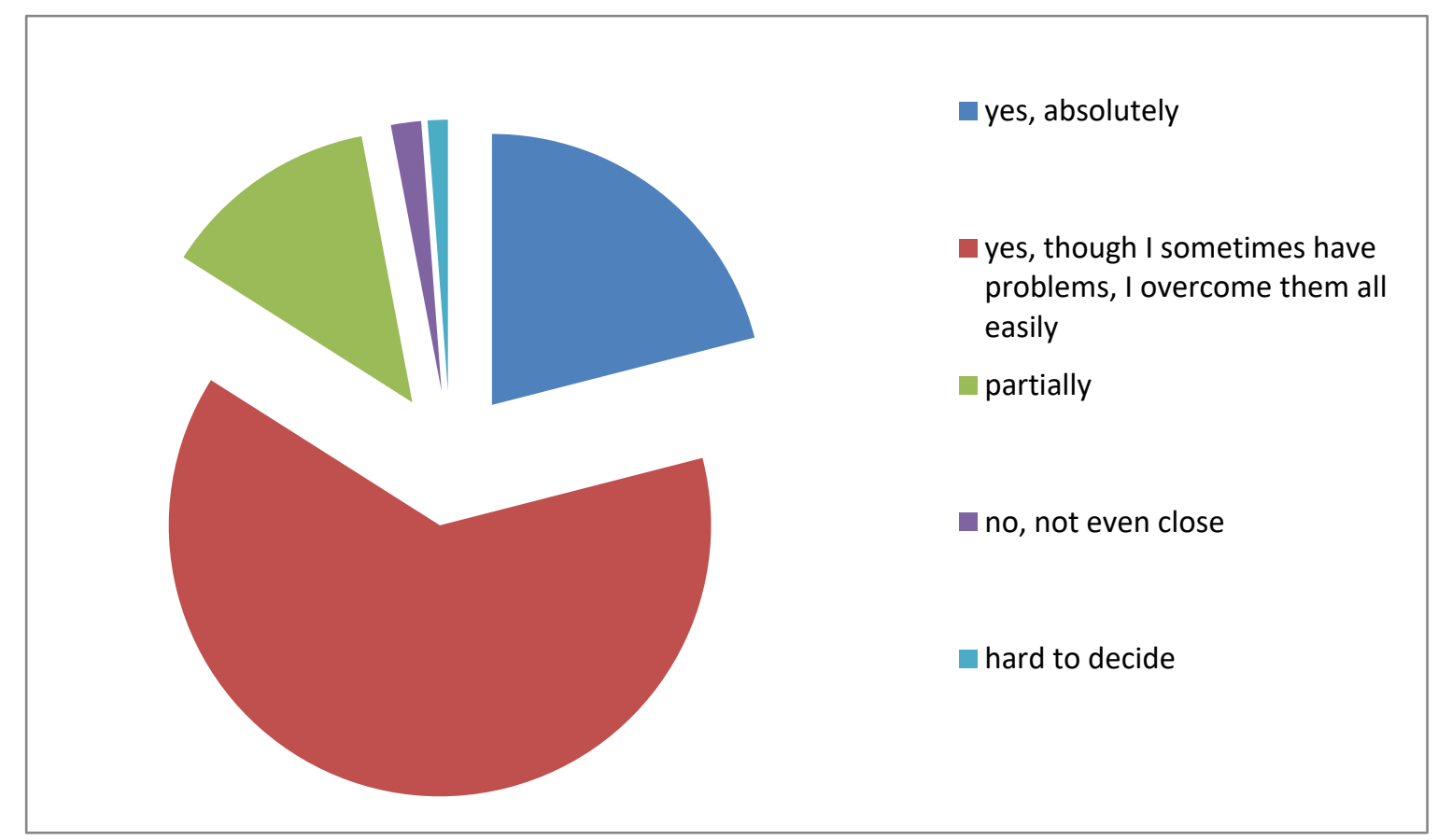

Diagram 2. Sufficiency of students' current digital competencies for distant learning

As we can see, the majority of respondents do not find problematic the distant learning because of their level of digital competencies, which turned out to be quite high. So we asked them whether these competencies are self-acquired or did they do special courses to enhance them. According to their answers only, $6 \%$ of students did 1-3 courses, and $94 \%$ of respondents acquired these competencies independently. Among this $6 \%, 1 / 3$ did the paid courses; others did free ones. We also asked our students whether they will study in this kind of courses if they have an opportunity. The results are pictured below in Diagram 3.

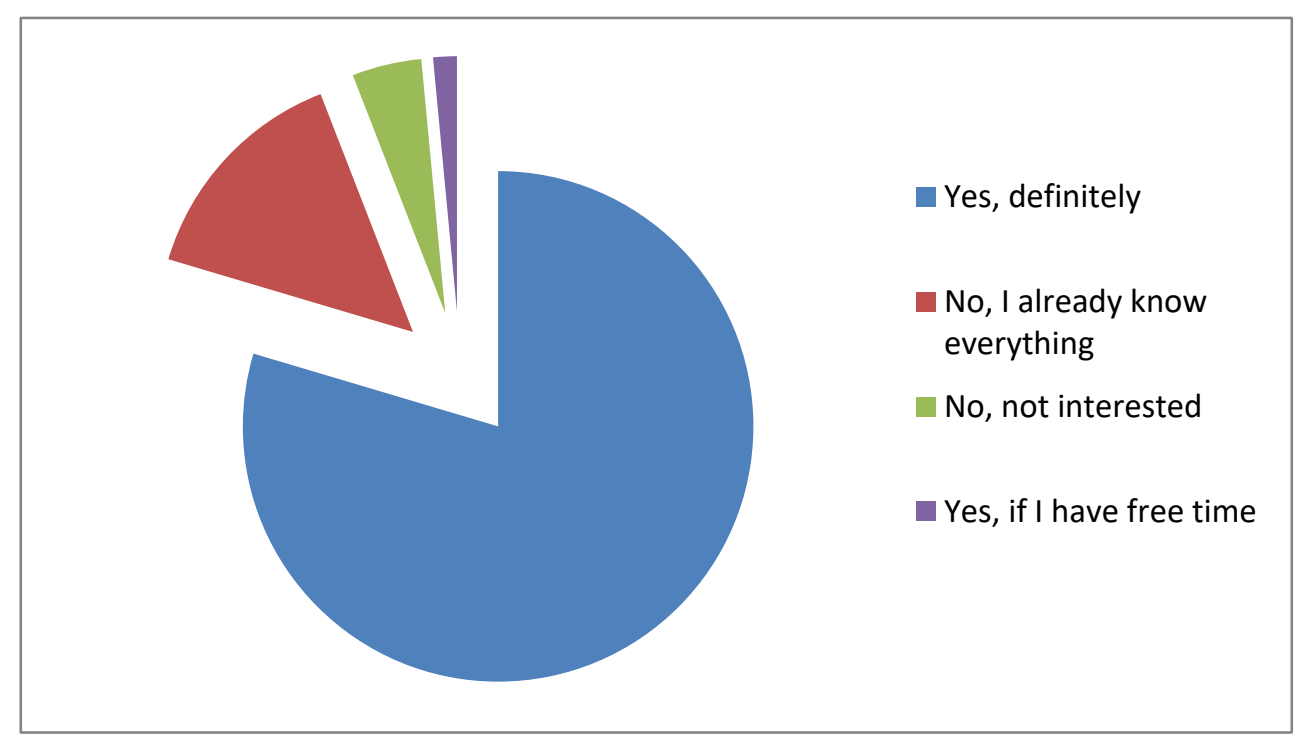

Diagram 3. Students' interest in doing courses on digital competencies 
Here we can observe that despite assessing their digital skills quite high, most of the respondents $(79,6 \%)$ showed interest in doing courses on digital competencies; $14,5 \%$ are sure their competencies are sufficient; $4,4 \%$ do not have an interest in it, and $1,5 \%$ will consider doing courses if they have extra free time.

Taking into account the above-described, we can conclude that our students' general and complementary digital skills required in distant learning are sufficiently high-leveled. However, this research alone cannot be considered enough to anticipate an overall tendency among youth, and further studies are required.

\section{Conclusion}

As can be observed in the results above, our students feel quite confident while distance studying due to the lockdown because of the country's pandemic situation.

Moreover, we require to highlight that in the majority of cases when students have some obstacles or any difficulties; they rely on their abilities to solve these cases, which is a very optimistic sign of students' becoming able to take accountability for their learning and development as a person and a specialist in their own hands. Nevertheless, we can also trace some problems with students' motivation to study, see tendencies to procrastinate, and not apply critical thinking, etc. Thus, we think that it is too early to move entirely from traditional education to a completely digital one. As is said in the ARUP Campus of the future 2018, on-campus experiences remain key (https://www.hse.ru). Obviously, digital education will play a significant role in providing affordable, accessible, and at the same time, high-quality education. However, traditional on-campus education can ensure exchange and sharing of experience, proper feedback, and producing new relationships, bonds, and cultural exchange, which are not possible and available in digital education today.

In our opinion, the best choice of education form from now on might be blended learning. It was studied and recommended by plenty of authoritative foreign and Russian scholars, among them V. Purnima, D. Clark, A. Rossett, F.Vaughan, L.V. Desyatova, U.I. Kapustin, and others. Blended learning combines the interaction of controversial elements, such as formal and non-formal learning, classroom work and independent learning, modern technologies and elements of traditional learning, and there is the interaction between students, the teacher, and interactive sources of information and every intrinsic part of it continuously interact with each other (Ivanova, 2018) helping to develop and educate modern competitive person, who will be able to learn and self-develop throughout his or her career and life.

\section{Acknowledgements}

The work is performed according to the Russian Government Program of Competitive Growth of Kazan Federal University.

\section{References}

12 resheniy dlya novogo obrazobaniya/12 solutions for new education: strategic research center report. Retrieved from https://www.hse.ru/data/2018/04/06/1164671180/Doklad_obrazovanie_Web.pdf

85\% Of Jobs That Will Exist In 2030 Haven't Been Invented Yet: Dell. Retrieved from https://www.huffingtonpost.ca/2017/07/14/85-of-jobs-that-will-exist-in-2030-haven-t-been-invented-yet-d_a_2 3030098/

Abdullina, L. R., Ageeva, A. V., \& Gabdreeva, N. V. (2019). Using the Flipped classroom model in the teaching of the theoretical disciplines (French language) at the university [Technologie de la classe inversee dans l'enseignement des disciplines theoriques (Fle) aux etudiants des universites]. XLinguae, 12(1XL), 161-169. https://doi.org/10.18355/XL.2019.12.01XL.12

Abrosimova, G., Kondrateva, I., Voronina, E., \& Plotnikova, N. (2019). Blended learning in university education. Humanities and Social Sciences Reviews, 7(6), 6-10. https://doi.org/10.18510/hssr.2019.762

Abrosimova, G. A., \& Kondrat'eva, I. G. (2018). Online Distance Learning Language: Educational Autonomy of Students. Vestnik NTsBZhD, 3(37), 5-11.

Ananin, V. E. et al. (2018). Digital company: transformation into new reality. Business Informatics, 2(44). https://doi.org/10.17323/1998-0663.2018.2.45.54 
Arup. Campus of the future. (2018). Retrieved from https://www.arup.com/perspectives/publications/research/section/campus-of-the-future-2018

Digital economy. (2019). brief statistical compilation/G. I. Abdrakhmanova, K. O. Vishnevsky, L. M. Gokhberg et al.; HSE, P. 96. Retrieved from https://www.hse.ru/data/2018/12/26/1143130930/ice2019kr.pdf

Digitalization in Education. $\quad$ Retrieved from https://www.plm.automation.siemens.com/global/en/our-story/glossary/digitalization-in-education/25307

Faleev, M. D., \& Faleeva, E. V. (2018). The use of digital technologies in the educational process of "elite education" of the Far Eastern State University of Railway Engineering // Modern educational process: questions of theory and practice proceedings of the Interregional Scientific and Methodological Conference, 76-79.

Gilmanova, A. A. (2018). Digital age and reading fiction: realities and perspectives. Kazan linguistic Journal, 1(1), 90-95.

Ivanova, O. U. (2018). Digital education: forms, technologies, monitoring. Linguistics and translation: collection of scientific articles, 7, 255-258.

Kivunja, C. (2015). Unpacking the Information, Media, and Technology Skills Domain of the New Learning Paradigm. International Journal of Higher Education, 4(1), 3-6. https://doi.org/10.5430/ijhe.v4n1p166

Kolykhmatov, V. I. (2018). Modern teacher digital skills in the condition of Digitalization of education. Uchenye zapiski universiteta imeni P.F. Lesgafta Uchenye zapiski universiteta imeni P.F. Lesgafta, 9(163), 152-158.

Kolykhmatov, V. I. (2019). Education of future: digitalization technologies. Modern education: content, technology, quality. Materials of the XXV International Scientific and Methodological Conference, 12-15.

Mayevskaya, E. L. (2018). Digital transformations in Germany: Universities in the era of digital technologies. Fundamental and applied social and humanitarian research. Proceedings of the II International Scientific Conference, 72-86. https://doi.org/10.23947/itno.2018.3.513-5199

Morozov, A. V. (2018). Changing the mentality of subjects of the educational process in the context of Digitalization of education. Socio-psychological problems of mentality, 146, 65-73.

Kireeva N., Zavyalov D., Saginova O., Zavyalova N. (2019). Students ' perception of social entrepreneurship.

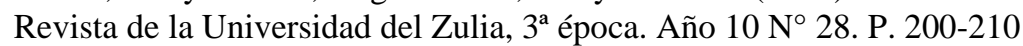

Samerkhanova, E. K., \& Imzharova, Z. U. (2018). Organizational and pedagogical conditions for forming the readiness of future teachers for project activities in the context of Digitalization of education. Vestnik of Minin University, 6(2). https://doi.org/10.26795/2307-1281-2018-6-2-2

Sovremennaya ciphrovaya obrazovatelnaya sreda v R. F./ Modern digital educational environment in the Russian Federation. Retrieved from http://neorusedu.ru/documents

Sulianta, F, Sapriya, S., Supriatna, N., \& Disman, D. (2019). Digital Content Model Framework Based on Social Studies Education. International Journal of Higher Education, 8(5), 3-11. https://doi.org/10.5430/ijhe.v8n5p214

Vichugova A. Digitalization. $\quad$ Retrieved from https://www.bigdataschool.ru/wiki/\%D1\%86\%D0\%B8\%D1\%84\%D1\%80\%D0\%BE\%D0\%B2\%D0\%B8\%D0 $\% \mathrm{~B} 7 \% \mathrm{D} 0 \% \mathrm{~B} 0 \% \mathrm{D} 1 \% 86 \% \mathrm{D} 0 \% \mathrm{~B} 8 \% \mathrm{D} 1 \% 8 \mathrm{~F}$

\section{Copyrights}

Copyright for this article is retained by the author(s), with first publication rights granted to the journal.

This is an open-access article distributed under the terms and conditions of the Creative Commons Attribution license (http://creativecommons.org/licenses/by/4.0/). 